upwards opposite it, in such a manner as to do away with all sharp angles or crannies, in which dust and other impurities can lodge. To do this in metal was easy, but ther was considerable difficulty with the webbed silk, a difficulty which Mr. Banks has successfully mastered.

The advantages are several. The catheter is extra strong where it used to be weakest. Cases of the breaking of a catheter at the eye while in use are not unknown; and everyone must have seen catheters worn and frayed most dangerously at that spot, which were yet in daily use by patients. The trick of knuckling over under pressure is also very troublesome to the surgeon. For patients who have to catheterise themselves this form of catheter has manifest advantages, as it combines flexibility and portability with ease in keeping it clean. The collection of filth to be found in any catheter after it has been a short time in a patient's charge is disgusting and dangerous, and I think all those who are inclined to attribute sepsis in the urinary tract to impure instruments, will welcome the modification I have described. A. OGInR WARD, M.B. and C.M. Edin.

Tottenham.

\section{THE HALL TYPE-WRITER.}

MessRg. Witherby, of 74 , Cornhill, the agents for this type-writer, have recently made an addition to the instrument which will very much increase its utility to those who suffer from paralysis. The addition consists of a ball, fixed to the handle, which can be easily grasped with either the left or the right hand, and is so placed that its weight makes the pointer rise from the holes without being lifted by the writer. At the same time it lessens the trifling force required to depress the handle and print the letter. The addition will render this convenient instrument suitable to many persons who could not have used it with the original handle,

\section{THE ITALIAN PRESS ON THE SANITARY CONFERENCE.}

THE leading journal in Rome, and indeed in Italy, is greatly exercised at what it deplores as the fiasco of the Sanitary Conference. "There is no use disguising it," says the Opinione--" the Conference has dissolved re infectâ; and though a diplomatic formula was contrived to veil the resultless issue, no one believes that it will ever meet again and come to any practical conclusion." The Opinione's chagrin is enhanced by the reflection that the initiative of convening the Conference was taken by Italy, and that the cause of the fiasco was due to the utter neglect on the part of the Italian Government to prepare a programme or to indicate the lines on which the Conference was to proceed. "When invitations," it says, "are issued to take part in a discussion, the invited participants are furnished with certain well-defined questions on which their judgments are to be evoled. But our Government, in its wisdom, prepared nothing, and it was a foreign delegate who tabled the proposals on which the discussion took place. Hence the whole proceedings were involved in confusion and disorder, and, to add to these, there were divergences among the Italian delegates, who thought more of their rival schemes than of their common action." Moreover, the Italian Government failed to do what other States on similar occasions have done: it failed to bring its delegates together, so as to put them in accord before the assembling of the Conference, and in this way came to a general understanding as to what their common country wanted or did not want; as to what they were to accept or to oppose. The Italian representatives thus pulled contrariwise, and, as the voting was by States, the deplorable spectacle was witnessed of Italy through one or more of her delegates supporting other interests than her own, these delegates dividing and reinforcing foreign camps. "How," asks the Opinione, " could we hope to come to any practical conclusion when the very Power which convened the Conference did not know her own mind?" The Pungolo of Naples, which reflects the opinion of the southern provinces, comments in a similar strain on the inconclusive collapse of the Conference. "And the most significant feature of all," it says, "is the fact that the proposal to suspend the sittings (the said proposal being but a diplomatic mode of declaring the Conference at an end) proceeded not from the English delegates, the sworn enemies of every hygienic precaution and safeguard, but from the German Ambassador, whose Government, at the London Conference on Egyptian affairs, was the first to provoke a Furopean deliberation on the sanitary question. The result, in consequence, could not have been more lamentable." According to another Italian organ, the Conference had become involved in quite a labyrinth of difficulties from which there was but one escape--the proposal made by the German Ambassador. The majority of the Italian journals seem convinced that the Conference will never reassemble, and, indeed, that it is scarcely desirable it should do so. Certainly Italy, and the Mediterranean Powers generally, were quite overborne in argument by the British minority, a fact of which they have betrayed their consciousness in other ways than by the unwarranted imputation of the Pungolo.

\section{SALICYLIC ACID IN RHEUMATISM.}

\section{To the Editor of Tre LANCET.}

Sir, -I have read with great interest Dr. P. W. Latham's communication to THE LANCFT of last week on rheumatic fever. I have always looked with considerable doubt upon the lactic acid theory of the causation of rheumatic fever, and the admirable way in which salicylates control, govern, and subdue this affection has for the past twelve months led me to consider whether the true theory of its causation might not be arrived at by examining into the chemical action of this body within the human organism. Knowing that when taken internally a considerable proportion of the salicylic acid administered appeared in the urine as salicyluric acid, and that in order to become such it was necessary that it should combine with glycocine, or some substance or substances closely allied to it, I was led to the belief, which I have frequently expressed to medical friends, that an excess of glycocine, or of some nearly allied body, was the cause of acute rheumatism. It may interest Dr. Latham to know that his theory of the causation of this disease, to the aid of which he has brought such exhaustive chemical and physiological knowledge, has been partially and crudely thought out by another. The theory Dr. Latham has advanced would be much enhanced if it could be proved that acute rheumatism is produced by the intra-peritoneal injection of glycocine and uric acid. So long ago as 1883 , and more especially after reading Dr. Garrod's Lumleian Lectures on Uric Acid, in which he detailed the influence of certain conditions and substances (notably benzoic and hippuric acids) upon the presence of this body in the urine, I believed that salicylates or their result when given internally-i.e., salicyluric acid-exerted a certain destructive or decomposing effect upon uric acid.

This belief was based upon the following premises:-

Firstly, that I had remarked the great benefit resulting from the use of the salicylate of soda in a case of gout which had recently come under my care, and also upon several cases of rheumatic gout.

Secondly, the close chemical relationship existing between the benzyl and salicylic groups of compounds, the members of the latter differing from the former by the substitution of an atom of hydrogen by the hydroxyl (OH), and the similarity of the action of the benzoates and salicylates when taken into the animal economy, suggested to me the belief that the therapeutic effect of the salicylates and salicyluric acid upon uric acid must he very much the same, as that of the benzates and hippuric acid already pointed out by Dr. Garrod.

Thirdly, I obtained the urine of a healthy man, and from this uric acid was readily thrown down by the ordinary mechod. From the same person under similar circumstances as to time, food, \&c., but to whom salicylate of soda had been administered, I procured another sample of urine. In this instance uric acid could not be obtained, no trace of it being discernible by the murexide test. Further experiments of this kind did not uniformly present the same results, but in all cases the amount of uric acid found in the urine containing salicyluric acid was very appreciably diminished. I may add that subsequent clinical experience has strengthened my belief in the above discussed property of salicylic acid and the salicylates. - I am, Sir, yours truly,

$$
\text { T. DAvifs Pryce, }
$$

June 24th, 1885, Resident Surgeon, the Dispensary, Nottingham. 